\title{
Observatorio
}

\section{El polimorfo libro electrónico}

\author{
Por José-Antonio Millán
}

Resumen: Repaso de las características más relevantes de los libros electrónicos, en sus dos acepciones: como aparatos de lectura y como contenidos. Se describen ventajas e inconvenientes, funciones, propiedad intelectual, aceptación, mercado... La disparidad de formatos, dispositivos y precios, y la inexistencia de una base social importante de uso de un dispositivo dedicado sólo a la lectura hacen que el libro-e sea todavía

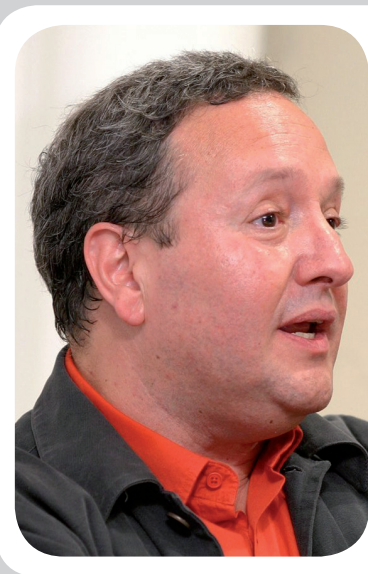

José Antonio Millán (Madrid, 1954) es licenciado en filología hispánica. Dirigió la primera edición en cd-rom del Diccionario de la Real Academia y creó el Centro Virtual Cervantes en internet. Ha colaborado frecuentemente en la prensa escrita divulgando temas de lengua (en El País mantuvo durante tres años la sección La palabra). En el 2005 apareció su libro Perdón imposible. Guía para una puntuación más rica y consciente, que gozó de una gran acogida y en seguida tuvo ediciones en México y Argentina. Ha publicado una veintena más de libros, tanto de ensayo como de narrativa, que se han traducido a muchas lenguas. Entre sus obras están la compilación La lectura en España. Informe 2002, Internet y el español (2001) y De redes y saberes. Cultura y educación en las nuevas tecnologías (1998). Forma parte del consejo científico de la Biblioteca Virtual Miguel de Cervantes y del consejo de la Sociedad para la Historia del Libro y de la Lectura. Mantiene un observatorio sobre diccionarios, lengua, edición electronica (y otras cosas) en: http://jamillan.com un producto incierto.

Palabras clave: Libros electrónicos, Libros-e, Mercado, Precios, Estrategias, Características técnicas.

\section{Title: The polymorphic electronic book}

Abstract: A review of the major characteristics of e-books, both as reading appliances and as content, includes a description of advantages and disadvantages, functionality, intellectual property, acceptance, market, and other considerations. The multiple different formats, devices and prices, and the absence of an important social base of users of this kind of device dedicated only to reading, make the e-book a product with a still uncertain future.

Keywords: Electronic books, E-books, Market, Prices, Strategies, Technical characteristics.

Millán, José-Antonio. "El polimorfo libro electrónico”. En: El profesional de la información, 2008, julio-agosto, v. 17, n. 4, pp. 369-371.

DOI: 10.3145/epi.2008.jul.01

DESDE HACE AÑOS se arrastra una duplicidad de sentidos para la expresión libro electrónico (libro-e, e-libro, e-book).

Se utiliza para hacer referencia [1] a las obras legibles en pantalla, descargables o no, imprimibles o no (por ejemplo, "un libro en pdf"), o bien [2] a un dispositivo dedicado, con pantalla y funciones especializadas en la lectura (por ejemplo, el Kindle). Estos dos sentidos, relacionados metonímicamente, ya operaban también para el libro tradicional. Éste es, para la Academia: "Obra científica, literaria o de cualquier otra índole con extensión suficiente para formar volumen" o bien "Conjunto de muchas hojas de papel u otro material semejante que, encuadernadas, forman un volumen"; es decir: de nuevo el contenido o el continente. Esta deriva actúa constantemente en este terreno: "un MP3" es tanto un archivo de sonido como un aparato que los lee.

En la acepción [1] del libro electrónico (las obras) nos encontramos con una proliferación de formatos y modalidades de acceso, muchas veces interconectadas. Un libro a la venta en Lulu.com puede leerse en pantalla, descargarse como pdf o imprimirse bajo demanda (momento en el que en rigor, dejaría de ser un libro-e). Hay que señalar que para la mayoría de los editores, distribuidores e intermediarios de material digital el término libro-e prescinde de la connotación de extensión que hemos visto que tenía en papel, e incluso del carácter unitario que le atribuyen leyes como la española; "obra científica, artística, literaria o de cualquier otra índole que constituye una publicación unitaria" (Ley 10/2007, de 22 de junio, de la lectura, del libro y de las bibliotecas, Artículo 2). Se llama e-book a cualquier cosa: desde un folleto, poema o cuento a un catálogo, revista o álbum de fotos.

Desde el punto de vista de la ergonomía de la lectura en pantalla, tan libro-e [1] son los html crudos de la Biblioteca Virtual Miguel de Cervantes como las ver- 
siones flash con giro de página de Issuu.com, pasando por las novelas para teléfono móvil o pda.

\section{"Los libros-e aparecen y desaparecen constantemente del mercado y de los medios de comunicación. El último ha sido Kindle, de Amazon"}

Llevamos más de treinta años conviviendo con obras literarias o de cualquier otro tipo para leer en pantallas de todos los tamaños. Pero los dispositivos dedicados (libro-e [2], a los que en lo sucesivo denominaremos $l i$ bro-e, e-book, etc., a secas, o sencillamente lector), de una década de antigüedad, aparecen y desaparecen constantemente del mercado y de los medios de comunicación. La última reencarnación de la idea ha sido Kindle, de Amazon, que ha despertado un ruido mediático muy grande, a pesar de que ya habían aparecido antes en el mercado otros dispositivos dedicados similares. La repercusión ha sido notable incluso en España, donde ni estaba a la venta ni había planes de que estuviera.

El hardware para lectura tiene varias características que podrían explicar su tradicional falta de éxito. Por un lado, en este momento de convergencia de funciones en un mismo aparato (el teléfono móvil hace también de emisor/receptor de mensajes cortos, de pda, cámara fotográfica, reproductor de música, plataforma de juegos, localizador geográfico...), el libro-e hace una sola cosa "almacenar gran número de libros para que los leamos", que además no parece tener excesiva demanda.

Pero vayamos por partes: la tecnología de tinta electrónica en la que se basa la mayoría de los libros-e actuales es excelente para la lectura (desde el punto de vista energético y ergonómico) pero pobre para otros usos: es monócroma, por ejemplo, con lo que los dispositivos lectores no son buenos para juegos. Ha habido intentos de dotarles de sonido (para obras multimedia y como lectores de MP3 no-librescos), pero como i-pod los libros-e resultan demasiado grandes.

Está también el problema de los archivos que se pueden leer en ellos. Muchos lectores sólo admiten formatos propietarios que incorporan DRM (digital rights management), que impide su copia (con lo que ello conlleva de pérdida de la inversión si la plataforma fracasa, imposibilidad de pasarlos a terceros, etc.), y graves limitaciones en su uso, como hacer que el archivo sólo pueda leerse en un dispositivo, o impedir la impresión de páginas. Por no hablar de las incompatibilidades internas: uno compra un archivo de la versión 6.0 de determinado formato... que le da problemas en un lector que funcionaba para la 3.0.
De los formatos propietarios el más famoso es Mobipocket, que compró recientemente Amazon. Los formatos ligados a libros-e concretos van parcelando el mercado en detrimento de las posibilidades de los usuarios. Kindle, por ejemplo, usa una variante de Mobipocket, pero no puede leer directamente archivos Mobipocket que su propietario pueda haber comprado para su pda, PC u otro lector. Hay sitios de venta de e-libros [1] que ofrecen hasta 12 diferentes formatos, lo que Tom Tivnan llama "e-Babel". Algunos libros (como Iliad), permiten visualizar también html o pdf, liberando por tanto el lector para obras abiertas en la Red y para usos privados.

La compra de un e-book [2] supone un considerable desembolso: 300 dólares (unos 192 euros) el Sony Reader, 359 dólares (unos 230 euros) el Kindle, 499 euros el Iliad más barato. Está claro que ningún usuario pagará un precio así si no va a poder disponer de obras para su aparato. Parece que Amazon ofrece para el Kindle 125.000 títulos, y entre ellos hay muchas obras de actualidad, best-sellers y títulos apetecibles para el mercado masivo. Otras plataformas menos poderosas que la gigantesca tienda virtual podrían no obtener tantos títulos.

Quien implante su lector y utilice además formatos propietarios puede crear un monopolio de facto. Ya hay denuncias de que Amazon está vendiendo las obras para su Kindle por debajo del precio que paga por ellas a los editores. Al tiempo, muchos e-books se venden con lotes de libro de regalo: el Sony Reader incluía cien clásicos y Papyre, 400... ¿Hay quien dé más?

\section{Adquisición de libros}

Desde el punto de vista de la obtención de obras, se dan situaciones curiosas: mientras que los editores estadounidenses controlan los derechos electrónicos de sus autores, y por tanto pueden negociar cesiones masivas para $e$-book, en el caso de los autores españoles (cuyos derechos digitales no tienen los editores) esto se convierte en una tarea que hay que hacer autor por autor, o con sus agentes, que no suelen ser muy amigos de tales cesiones. Por cerrar este apartado, recordemos que la Web es hoy en día un reservorio de lectura quizás más grande que el mundo editorial, y que los libros-e que leen formatos abiertos pueden descargar incontables páginas y blogs para su lectura, y no sólo (caso de Kindle) los que quiere el proveedor.

Otra cuestión nada trivial es la vía de obtención de las obras: la mayoría de los libros-e requieren conexión a un PC para bajarse/comprar obras, mientras que Kindle optó por conexión directa vía línea telefónica móvil. En un mercado que cada vez opta más por la inmediatez de la compra (mando un sms y me bajo una canción), la intermediación penaliza al producto. 
Desde el punto de vista de las funcionalidades de estos aparatos, hay que tener en cuenta que bajo el término lectura se agrupan muchas operaciones, no todas las cuales se limitan a recorrer secuencialmente los caracteres en la pantalla: están los subrayados, anotaciones, extracción de resúmenes o citas, búsquedas, etc., que caracterizan no sólo la lectura técnica o científica, sino también la de fruición, cuyo componente social (recomendar un libro, enviar un fragmento) nunca se recalcará lo suficiente... La realización de estas operaciones complementarias, su salvaguarda posterior y su comunicación a terceros suele ser dificultosa, incluso para archivos abiertos, en dispositivos que por lo general aún carecen de un diseño óptimo de interfaz y funciones.

\section{"¿Para qué queremos un aparato tan grande como un laptop que sólo sirve para leer libros?"}

Muchos laptops tienen hoy pequeñas dimensiones, y muchos programas extendidos (empezando por Word y Acrobat) tienen funciones de presentación de texto orientadas a la lectura más que la edición. ¿Para qué queremos un aparato tan grande como un laptop pero que sólo hace una función? Para complicar la cosa, hay ordenadores portátiles que se presentan como e-books ( $\sin$ mencionar el equívoco creado por el nombre del portátil MacBook), como el famoso ordenador para el Tercer Mundo de Negroponte, el Olpc, que insiste en difundir sus funciones de lectura de libros. En su última reencarnación aparece como una pantalla doble que imita la familiar disposición de páginas enfrentadas que desde hace siglos caracteriza al códice...

Porque ésta es otra cuestión que ronda tanto a los libros-e [1] como a los libros-e [2]: todos se sienten atraídos por la forma clásica del libro: sus dimensiones, la proporción márgenes/texto, la doble página enfrentada, el giro de hojas. ¿Son realmente necesarias estas cosas para la utilización de textos electrónicos? Digamos que el libro tradicional, que nace con el manuscrito y se divulga con la imprenta, es un objeto muy depurado (perfecto como un cuchillo, dice el diseñador Yves Zimmermann: ¿qué vas a quitarle o añadirle?), y además lleva consigo siglos de prácticas lectoras y prestigio añadido. No es extraño que su influjo persista, y seguir sus pasos probablemente puede ahorrar ciertos problemas.

Pero la clave de la evolución futura del dispositivo dedicado para la lectura probablemente esté en un hecho que señalaba Cory Doctorow: el mundo del libro tiene un peso relativamente pequeño en el conjunto de los negocios actuales: música, juegos, ofimática... Esto tiene dos implicaciones: que la industria no puede subvencionar al dispositivo lector (la consola tiene un precio artificialmente bajo porque fomenta el gasto en juegos, y la impresora puede hasta regalarse, porque el gran gasto va a estar en la tinta). Los libros, en este caso por desgracia, son baratos, y no se consumen tanto como la música o los juegos. Además (de nuevo Doctorow), en las factorías de la lejana China donde se fabrican desde las consolas hasta los libros-e, éstos tienen que competir con productos de venta muchísimo más masiva. Esto explica las frecuentes roturas de stock que han padecido tradicionalmente. El libro-e estaría, según él, entre la espada del fracaso de público y la pared del desabastecimiento...

Como se ve, la situación de los contenidos textuales/ gráficos en el medio digital es altamente movediza, lo que no contribuye a aclarar los modelos de negocio que puedan surgir a su alrededor. ¿Qué venden exactamente los e-books? ¿Almacenamiento y portabilidad? ¿Acceso inmediato para las compras impulsivas? ¿Interacción entre grupos de usuarios (por ejemplo, en usos docentes)? ¿Usos privados? (un nicho creciente de usuarios son los propios editores y agentes, que prefieren llevar un e-book con los manuscritos y obras sobre las que tienen que decidir, mejor que una pila de papeles).

Para complicar las cosas, no pasa un mes sin que aparezca un nuevo modelo de lector, la mayoría basados en la tecnología de tinta electrónica. Aparte de los ya mencionados están: BeBook, Hanlin eReader, CyBook, Papyre, Vizplex, Nuut, Apollo, Cellular Book, STAReBOOK, Flepia, iBook... Muchos de ellos son variantes del mismo aparato chino o coreano, con pequeños retoques $\mathrm{o}$ adaptaciones locales de su distribuidor.

Así pues, a la disparidad de formatos se une la de dispositivos y precios. Mientras tanto, la base social del uso de un dispositivo dedicado para la lectura y las prácticas ligadas a él no han comenzado a despegar significativamente. De hecho, no tenemos aún elementos para decidir si el libro-e es (adaptando una cínica definición que proviene de otro campo) una solución para un problema que nadie tiene, o bien la mayor revolución contemporánea del mundo de la edición.

$\mathrm{O}$ algo entre medias, por supuesto...

Este artículo está sujeto a la licencia de Creative Commons Reconocimiento-No comercial-Compartir bajo la misma licencia 2.5 España http://creativecommons.org/licenses/by-nc-sa/2.5/es/deed.es

\section{José-Antonio Millán \\ librosybitios@jamillan.com \\ privado@jamillan.com \\ http://jamillan.com}




\section{Proquest}

\section{Safari Books Online}

la información y visión de los mejores

expertos en tecnología y negocios

- Miles de libros de entre los más vendidos

y prestigiosos en tecnología y negocios

- Contenido exclusivo de las editoriales líderes

en tecnología Pearson y O’Reilly Media
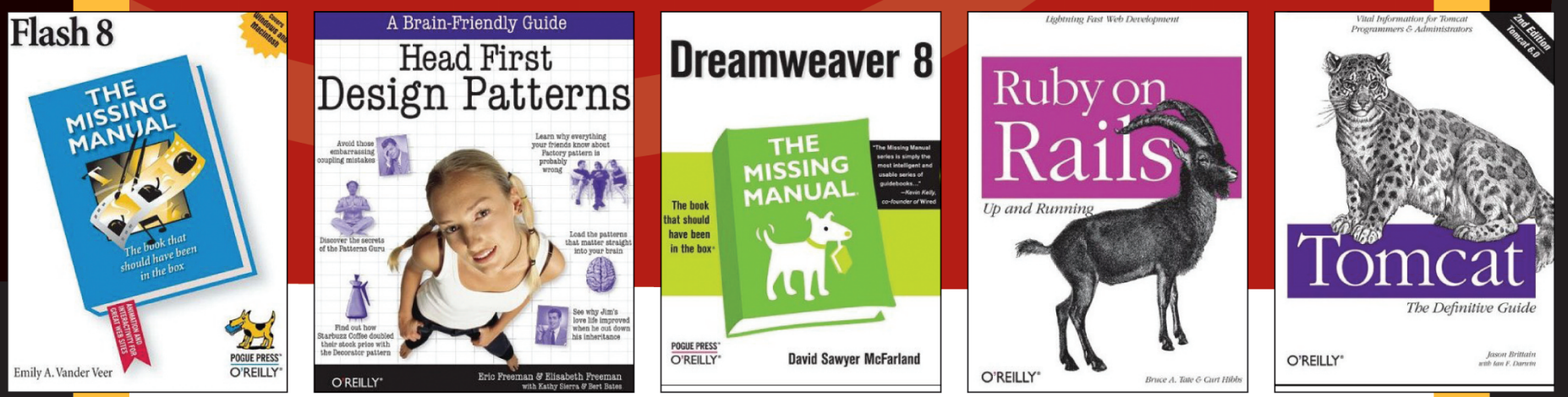

Para solicitar un periodo de prueba escriba a editor@spain.proquest.com con la referencia AD 81708 